\title{
Anglicismos léxicos en español y en eslovaco: un estudio contrastivo
}

Palabras clave: anglicismo, cognado equívoco, español, eslovaco, calco.

\section{Introducción}

Una de las características más universales del léxico de las lenguas de todo el mundo en los siglos XX y XXI es el flujo creciente de anglicismos. Se han escrito muchos artículos y monografías acerca de ellos en diferentes aspectos, tanto en español como en eslovaco. En este trabajo, a diferencia de la mayoría absoluta de los demás, ofrezco el punto de vista confrontativo. Este artículo forma parte de un proyecto cuyo objetivo es contrastar el español y el eslovaco en el nivel lexicológico y semántico ${ }^{1}$. Muchos anglicismos léxicos son verdaderos internacionalismos (por ejemplo tennis, football, jazz, whisky, coctail, scanner, laser, bippy, ketchup, etc.), se utilizan en todas las grandes lenguas europeas $^{2}$. Debido a ello podemos tender a pensar que los anglicismos en nuestra primera lengua deben tener su correspondencia en la segunda. En la mayoría de los casos es cierto. No obstante, no siempre es así. La identificación, clasificación y análisis de esta asimetría en el uso de los anglicismos españoles y eslovacos es el tema y el objetivo del presente trabajo, aunque soy más que consciente de que la lista aportada no es nada exhaustiva. Se trata, más bien, de un primer acercamiento al tema, y es necesario tener en cuenta a su vez que

$1 \quad$ El proyecto es realizado por la Sección de Hispanística de la Facultad de Filosofía de la Universidad Comenius de Bratislava. Sus resultados se aplicarán también en el proceso didáctico de su programa de estudios de Traducción e Interpretación.

2 No mencionamos los idiomas no europeos, simplemente porque en poquísimas ocasiones un hispanista eslovaco o eslovaquista / eslavista hispanohablante los domina y puede recurrir en su aprendizaje a los conocimientos de lenguas no europeas. 
dada la dinámica de los procesos de inmigración léxica, la situación cambia relativamente rápido.

En cuanto al español, me centro en el español peninsular actual, aunque incluyo un par de referencias a las variantes hispanoamericanas que, debido a la extensión y carácter del artículo quedan, desgraciadamente, al margen.

Los ejemplos utilizados se estructuran de la forma siguiente: los ejemplos aparecen en cursiva; aparecen en cursiva y en negrita las palabras y expresiones contrastadas de las dos lenguas en cuestión, en primer lugar la(s) palabra(s) en español, y en segundo lugar en eslovaco (con la excepción de los casos en los que el español carece del anglicismo o del calco del anglicismo).

\section{Diferencias}

\subsection{Diferencias fonortográficas}

A veces el mismo anglicismo se usa en las dos lenguas en cuestión, sin embargo en estos casos también puede haber numerosas diferencias, sobre todo a nivel de grafía y de pronunciación. Las diferencias de este tipo entre el eslovaco y el español raras veces dificultan y casi nunca imposibilitan la comunicación, por ello voy a mencionar tan solo un par de diferencias a fin de ejemplificar el fenómeno. Los anglicismos difieren en el modo y/o grado de adaptación gráfica (compárese la adaptación gráfica cero de la palabra rickshaw en español y la forma asimilada rikša en eslovaco ${ }^{3}$ ). Hay algunas pautas que son predecibles, como lo es en el caso del español la prótesis de una $e$ a principio de palabra si aparece el grupo consonántico $s+$ otra consonante: smoking < esmokin, standard < estándar, scanner < escáner, to sniff > esnifar. A veces esta adición no se realiza a nivel gráfico, sino solo en la pronunciación: all star [olestár]). No obstante, en el caso de muchos anglicismos el proceso de adaptación no está aún terminado, lo que conlleva la inestabilidad gráfica, es decir, la existencia de más variantes: basketball / basket-ball / basquetbol, videoclip / video-clip / vídeo-clip.

En lo que respecta a la pronunciación, el eslovaco suele mantener más fielmente los sonidos originarios. Las mayores diferencias, que suelen ser de carácter

3 El inglés sirvió de lengua intermediara, es una palabra de origen nipón, jinrikisha es un compuesto de jin 'hombre' + riki 'fuerza' + sha 'carruaje'. http://etymonline.com/index. php?term=rickshaw\&allowed_in_frame $=0$ [12.6.2015].

Las palabras eslovacas se han tomado del corpus nacional eslovaco: http://korpus.juls.savba. sk/, de los diccionarios académicos: http://slovniky.juls.savba.sk/, ambos disponibles en la página web del Instituto Lingüístico de L'udovít Štúr de la Academia Eslovaca de Ciencias o de los ejemplos recopilados durante la investigación propia del autor. 
regular, estriban en el empleo de sonidos distintos. Por ejemplo, el grafema $u$ que en ciertos casos se pronuncia en inglés como la vocal plana sonora [a] se suele mantener en eslovaco y en español hay tendencias a castellanizarla y pronunciarla como la vocal cerrada posterior redondeada [u]. Aunque a menudo se dan las dos opciones (entre corchetes aparece la pronunciación española, le sigue la eslovaca): buffer $>[$ bufer $]-[$ bafr $]$, dumping $>[$ dumpin / dampin $]-[$ dampink], rugby > [rugbi] - [ragbi] etc.

O el grafema $a$, que a veces se pronuncia en inglés como la vocal casi abierta anterior no redondeada $[\mathfrak{x}]$, se suele pronunciar en español como una vocal abierta anterior [a], mientras que en eslovaco predomina en este caso la vocal anterior semicerrada $[\mathrm{e}]$ : crack $>[k r a k]-[k r e k]$, fashion $>$ [fáfion / fásion] $[\mathrm{fe} f \mathrm{n}]$, feedback $>[$ fídbak $]-[$ fi:dbek], freelance $>[$ frílans] $-[$ fri:lens $]$, rock and roll > [rokanról] - [rokenrol], sandwich > sándwich [sángüit] - [sendvit]] etc.

También se da en español con frecuencia la intercalación de [e] u [o] en grupos consonánticos: beautiful people > [biutiful pipol] - [biu:tifl pi:pl], Google > [gugel $]$ - [gu:gl], paddle > [pádel] - [pedl] etc.

En cuanto a algunas consonantes fricativas y africadas, el español carece de varios fonemas que a su vez comparten el eslovaco con el inglés. De ahí que en eslovaco se pronuncien estos sonidos más o menos idénticamente al inglés, mientras que el español usa otras consonantes a su disposición, las que más se asemejan al original, por ejemplo:

a) fricativa prealveolar sonora $[z] \rightarrow$ en español no se sonoriza $[s]:$ looser $>$ lúser [lúser] - lúzer [lu:zer], laser > láser [laser] - laser [laser / lejzer].

b) africada postalveolar sonora [dz], representada por el grafema inglés $j \rightarrow$ en español pronunciada como africada palatal sonora [j]], a veces se castellaniza al emplear el grafema y: banjo > banjo / banyo [bánjo] - bendžo [bendzo], jazz > jazz / yas [jás] - džez [dzez], jogging > joggin (g) [jóguin] - džoging [dzogink], etc.

En las siglas de origen inglés también encontramos diferencias:

$V I P$, se lee secuencialmente en español y se deletrea a la inglesa en eslovaco [bip] - [vi-ái-pí]

$D V D$, en ambas lenguas se usa el deletreo propio [deuvedé] - [dévédé]; en eslovaco, a veces, en el lenguaje informal y por la influencia del checo, se puede usar el deletreo inglés añadiendo un sufijo: dívídičko. 


\subsection{Diferencias regionales dentro del territorio hispanohablante}

Resultaría impensable incorporar aquí las variantes de 20 países hispánicos, y aunque hemos escogido para nuestro análisis el español peninsular, no deberíamos pasar por alto todo un continente con más de 400 millones de hispanohablantes. Además, una gran parte de ellos vive en países que por su cercanía o influencia histórica de Estados Unidos forma un caso especial en cuanto a los anglicismos. Es el caso de México, Puerto Rico y Cuba, entre otros ${ }^{4}$, y en menor medida también de toda Centroamérica.

A veces la diferencia estriba tan solo en el nivel fónico; normalmente en las variantes hispanoamericanas la pronunciación de los anglicismos guarda más fidelidad con el original: wifi [guafai] - [güifi]. En muchos casos se usa solamente el anglicismo en Hispanoamérica:

$$
\begin{aligned}
& \text { concreto 'hormigón'< concrete } \\
& \text { living 'sala de estar' (Argentina, Uruguay, Chile) < living room } \\
& \text { lonche 'comida del mediodía, especialmente si es frugal' } \\
& \text { (México, Cuba, Venezuela) < lunch } \\
& \text { plomero 'fontanero'< plumber } \\
& \text { rentar 'alquilar' < to rent }
\end{aligned}
$$

Aunque también se dan casos opuestos, por ejemplo en la señal de detención obligatoria en España vemos escrita la palabra inglesa $S T O P$ en el octágono de fondo rojo, mientras que en México y Centroamérica pone ALTO y en los demás países hispanoamericanos es PARE.

\subsection{Diferencias socioculturales}

A la hora de analizar las diferencias semánticas hay que tener en cuenta el contexto y las desigualdades en la relevancia o las asociaciones que conlleva el anglicismo en cuestión. El pádel es mucho más popular en España que el paddle en Eslovaquia. Y el béisbol, por ejemplo, es el deporte más popular en Cuba

4 Un caso excepcional son las comunidades hispanohablantes dentro de EE.UU. Tanto las históricas (población hispanófona en el territorio que históricamente pertenecía al virreinato de Nueva España y después de las guerras de independencia hispanoamericanas a México) como las nuevas, resultado de la inmigración durante los siglos XX y XXI. 
o en Nicaragua. Aunque del mismo juego se trate, socioculturalmente no corresponde a su equivalente denotativo en eslovaco: bejzbal. En estos países está a la misma altura que el fútbol en Eslovaquia (o en España). O, por ejemplo, el segundo deporte más popular de Eslovaquia, bockey (sobre) bielo - l'adový bokej, es el deporte nacional, mientras que en todos los países hispanohablantes es un deporte marginal y exótico5. Contrario es el caso de la medida de peso libra, que no forma parte de la realidad extralingüística en Eslovaquia, mientras que en varios países hispanoamericanos se usa, por la influencia estadounidense, la libra y no el kilogramo (Nicaragua, Panamá, Cuba, etc.). Otro tipo de diferencia consiste en el contexto temático distinto en el que el anglicismo suele usarse. Veamos el anglicismo draft ('sorteo anual por las ligas deportivas para seleccionar nuevos jugadores procedentes de las ligas universitarias o del extranjero'). En España, el mayor interés se presta al draft de la Asociación Nacional de Baloncesto (NBA) y en Eslovaquia al celebrado por la Liga Nacional de Hockey (NHL).

\subsection{Diferencias formales}

Para adaptar el anglicismo se añaden elementos domésticos, siendo uno de ellos los afijos. En muchos casos un sustantivo inglés recibe un sufijo en eslovaco y en español no:

(calzoncillos) bóxer - boxerky, < boxer shorts, boxers;

cheerleader - čirlíderka (calcos: animadora - roztlieskavačka), < cheerleader;

fan, en el ámbito deportivo también se usa bincba, préstamo interno de la variante argentina y uruguaya (Gómez Capuz, 2004: 33) - fanúšik, < fan (abreviado de fanatic 'fanático');

bamburguesa - bamburger (en el registro informal se aplica en ambas lenguas el acortamiento inicial, que surgió en inglés: burger), < bamburger;

(código) morse - morzeovka, < Morse (code).

En el argot eslovaco, aparte de la sufijación, primero se suele llevar a cabo el acortamiento final de la palabra: McDonalds > mekdonald > mekáč, bamburger > bambáč, multiscreen cinema $>$ multikino $>$ multák.

5 Se practica, como deporte muy minoritario solo en dos países hispanohablantes, en España y en México.

6 Hay excepciones en las que ocurre lo contrario, de los ejemplos aquí presentados es el caso de bamburguesa - bamburger. 
En otras ocasiones se reemplaza el sufijo inglés en una de las lenguas: scouting (movement) > scoutismo ${ }^{7}$ - skauting, stripper > stripper ${ }^{8}$ com. - striptér $m$, striptérka f; en una de las lenguas el anglicismo queda íntegro, en la otra se emplea un híbrido (una parte se traduce): plexiglas (nombre de marca, abreviado de plexiform glass 'vidrio flexible') > plexiglás - plexisklo; hay casos en los que en una de las lenguas se usa solo la forma univerbizada: Jobn Lennon specs > gafas Lennon - lenonky.

\subsection{Diferencias semánticas: cognados equívocos}

Los anglicismos aquí presentes son los llamados 'falsos amigos' que se han desarrollado de manera distinta en cada una de las lenguas receptoras:

\begin{tabular}{|l|l|l|l|l|}
\hline español & traducción eslovaca & eslovaco & traducción española & palabra inglesa \\
\hline bike & motorka & bajk & bici & $<$ bike \\
\hline ténder & tender, zásobník & tender & $\begin{array}{l}\text { 1. ténder 2. con- } \\
\text { curso (público), oferta } \\
\text { pública }\end{array}$ & $<$ tender \\
\hline ticket & lístok & tiket & boleto de lotería & $<$ ticket \\
\hline tramp & $\begin{array}{l}\text { trampová / túlavá lod' } \\
\text { (mercante sin líneas } \\
\text { regulares ni carga- } \\
\text { mento fijo) }\end{array}$ & tramp & vagabundo & $<$ tramp \\
\hline
\end{tabular}

Aparte de los cognados falsos tenemos casos en los que el anglicismo ha desarrolado un significado adicional, ausente en la otra lengua:

\begin{tabular}{|l|l|l|l|l|}
\hline Español & significado & eslovaco & significado & palabra inglesa \\
\hline Crack & $\begin{array}{l}\text { 1. clorhidrato de } \\
\text { cocaína } \\
\text { 2. quien destaca en } \\
\text { algo }\end{array}$ & crack & $\begin{array}{l}\text { 1. clorhidrato de co- } \\
\text { caína } \\
\text { 2.- }\end{array}$ & $<$ crack \\
\hline Túnel & $\begin{array}{l}\text { 1. paso subterráneo } \\
\text { 2.- }\end{array}$ & tunel & $\begin{array}{l}\text { 1. paso subterráneo } \\
\text { 2. fraude de los } \\
\text { fondos comúnes }\end{array}$ & $<$ tunnel \\
\hline
\end{tabular}

\subsection{Diferencias en el empleo de calcos}

Varias palabras o expresiones que usamos en español o en eslovaco son tan solo calcos del inglés, es decir, calcos estructurales: skyscraper > rascacielos, basketball

7 El sinónimo castellanizado es escultismo.

8 Otras variantes: la stripteuse, el stripteaser. 
> baloncesto, freetbinker > librepensador o semánticos: ratón en el significado de 'dispositivo del ordenador que mueve el cursor'.

Hay casos en los que una de las dos lenguas confrontadas usa un calco del inglés y la otra no: gold digger 'mujer que trata de casarse con un hombre rico' > zlatokopka-cazafortunas / aventurera / sacacuartos

Otras veces se usan tanto el anglicismo como el calco que ha surgido como medida de naturalización del anglicismo íntegro (préstamo de forma y de significado). En muchos casos existen los dos sinónimos (el anglicismo íntegro y el calco) en ambas lenguas: link > link / enlace - link / odkaz, fair play > fair play / juego limpio - fair play / čistá bra. A veces el calco o el sinónimo existe solamente en una de las dos lenguas:

a) en español sí - en eslovaco no

Los más conocidos son los ejemplos de los nombres de deportes que se originaron en el mundo anglosajón:

football > fútbol / balompié - futbal

basketball > básquetbol / baloncesto - basketbal

voleyball > voleibol / balonvolea - volejbal 9

Otros ejemplos:

airbag > airbag / bolsa de aire - airbag

brainstorming > brainstorming / lluvia de ideas, tormenta de ideas -

brainstorming

cowboy > cowboy / vaquero - kovboj

film $>$ film (e) / película - film

foul $>$ foul / falta - faul $^{10}$

skate (board) > skate (board) / monopatín - skejt(bord)

sprinter > esprinter / velocista - šprintér

9 En varias de las lenguas eslavas sí que existen calcos de los nombres de juegos de pelota, eso sí, de diferente grado de frecuencia de uso o de anticuación: football - checo kopaná, polaco pitka nożna, croata, esloveno nogomet, etc.; basketball - checo košíková, croata, esloveno košarka, etc. De las lenguas románicas podemos mencionar el italiano en el que se usa la palabra calcio que no es un calco de inglés sino el nombre de uno de los juegos de pelota históricos practicado en el territorio italiano actual.

10 En el lenguaje formal o en los textos oficiales se puede reemplazar el anglicismo eslovaco faul por expresiones pluriverbales descriptivas: nedovolený zákrok (en fútbol) u osobná cbyba (en baloncesto). 
Cuando existen las dos opciones, hay que tomar en consideración la frecuencia de uso de los sinónimos. Por ejemplo, es muy escaso hoy en día el uso de balompié, se registran tan solo 547 casos en el corpus CORPES XXI vs. fútbol 22.462, a diferencia de baloncesto 2.282 vs. básquetbol 591 (más básquet 331, basket ${ }_{154}$, basketball 46 , básketbol 5$)^{11}$.

b) en eslovaco sí - en español no

\section{Murpby's Law > ley de Murpby - Murpbybo zákon / zákon schválnosti}

En ocasiones en una de las lenguas predominó el calco y en la otra el anglicismo: fin de semana - víkend, del inglés weekend (el calco koniec týždña no sirve, porque en la mayoría de los casos se interpreta como el fin de la semana laboral, es decir 'el viernes'). En otros casos el anglicismo adquiere el valor de término genérico y en la otra se especializa semánticamente y se actualiza solo en el contexto apropiado:

gentleman 'caballero británico' - džentlmen 'caballero en general' $<$ inglés gentleman

booligan 'hincha de fútbol inglés, caracterizado por su comportamiento violento' - chuligán 'gamberro', 'vándalo' en general < booligan

También ocurre que en una de las lenguas el anglicismo haya reemplazado la palabra original o al menos haya marginado su uso. El caso palmario son los puntos cardinales en español, el inglés es la lengua de origen y el francés sirvió de lengua intermediaria:

este $m$ ( $<$ francés est < inglés antiguo ēast, id. ${ }^{12}$ ), levante, oriente - východ

norte $m$ ( $<$ francés nord < inglés antiguo norp, id.), septentrión - sever

oeste $m$ (<francés ouest < inglés antiguo west, id.), poniente, occidente - západ

sur $m$ (< francés sud < inglés antiguo sûp), austro, ostro - jub

Aquí me gustaría subrayar una diferencia importantísima entre el léxico español y el eslovaco con respecto a los vocablos del inglés. Una gran parte del

11 http://www.rae.es/recursos/banco-de-datos/corpes-xxi [12.06.2015].

12 Los datos etimológicos entre paréntesis han sido tomados de la versión electrónica de DRAE: http://www.rae.es/recursos/diccionarios/drae [12.06.2015]. 
vocabulario inglés es de origen latino o francés, lo que da lugar a una percepción diferente de los mismos. En varias palabras acuñadas en inglés que se basan en las raíces francesas o latinas no se siente tanto su carácter extranjero: computer (nombre agente de compute < francés computer < latín computare 'contar', 'computar'13) > computadora ${ }^{14}$; revolver (< francés antiguo revolver < latín revolvere 'revolver'15) > revólver. Por otro lado, hay muchos más casos de cognados equívocos o 'falsos amigos' entre inglés y español que entre inglés y eslovaco. Es el resultado del hecho de que numerosas palabras compartidas han seguido rutas divergentes en su desarrollo semántico. Los casos más trillados son tal vez los siguientes: exit 'salida' - éxito 'succes', embarrased 'avergonzado' embarazada 'pregnant', actual 'verdadero' - actual 'current', 'present', library 'biblioteca' - librería 'bookstore'. Y en algunos casos ya podemos ver que, pasada la fase de cognado equívoco, poco a poco se van aceptando los significados inducidos por el modelo inglés (ejemplos tomados de Gómez Capuz, 2005: 49):

convencional 'fruto de una convención' + el significado anglicado de 'armamento tradicional' < conventional impacto 'choque de un proyectil' + el sgdo anglicado de 'golpe emocional' < impact

villano 'plebeyo', 'rústico' + el sgdo. anglicado de 'el malo de la película' < villain

\subsection{Pseudoanglicismos}

Es una categoría muy curiosa. Consta de términos aparentemente originarios del inglés, pese a que en realidad no existe nada parecido en dicha lengua. Son palabras acuñadas en francés que usan morfemas propios del inglés, en rigor deberían considerarse galicismos (Gómez Capuz, 2005: 63/64). Los incluimos en nuestro artículo porque en estos casos el eslovaco suele emplear un anglicismo correcto:

footing ${ }^{16}$ - kondičný / rekreačný beh, džoging, en inglés es jogging, footing en inglés significa 'punto de apoyo', 'asidero', figurativamente también 'base', 'cimientos', 'posición';

13 http://etymonline.com/index.php?term=computer\&allowed_in_frame=o, http://etymonline.com/index.php?term $=$ compute\&allowed_in_frame $=0$ [12.06.2015]

14 Palabra usada en Hispanoamérica, en España predomina ordenador.

15 http://etymonline.com/index.php?term=revolve\&allowed_in_frame=0 [12.06.2015].

16 También se emplea jogging. 
parapenting ${ }^{17}$ - paraglajding, en inglés es paragliding, para-penting en inglés se refiere a una modalidad de esquí en la que el deportista se lanza en paracaídas (Rodríguez González, 1997: 376);

récordman ${ }^{18}$ - rekordér, en inglés es record bolder;

rent-a-car - požičovňa áut, en inglés es car rental agency;

Por analogía surgió en español actual el falso anglicismo puenting ${ }^{19}$ - en eslovaco bungee jumping, del inglés bungee jumping.

\subsection{Siglas inglesas}

Aparte de las diferencias de pronunciación ya mencionadas, existen varios casos de uso diferente de las siglas. En eslovaco se emplean las siglas internacionales, entiéndase inglesas, mientras que en español se emplea el orden inverso. Este hecho se debe en gran parte al francés, una lengua mundial de prestigio y tradicionalmente de gran peso cultural y diplomático. Siendo también una lengua románica con mecanismos de creación de palabras pluriverbales muy parecidos, comparte con el español numerosas siglas y así ayuda a mantener las siglas españolas frente a la tendencia unificadora de usar las siglas inglesas: OTAN - NATO, ADN - DNA, EE.UU. - USA, SIDA - AIDS, VIH - HIV, OVNI - UFO, etc.

\section{Anglicismos ${ }^{20}$ que se usan solo en español}

bacon $m$ 'tocino entreverado con magro ahumado y salado' (< bacon, id.) - anglická slanina;

cachear tr. 'registrar' (< to catch 'coger', 'agarrar', 'tomar', en inglés se emplea to frisk, to search) - prebl'adat';

chutar tr. / intr. 'lanzar el balón con el pie' (< to shoot 'disparar')

- kopat', strielat';

córner $m$ (< corner) / sin.: saque de esquina - robový kop, rob;

cúter $m$ (< cutter $)$ - orezávač;

17 También se emplea paragliding.

18 También plusmarquista.

19 También se emplea bungee jumping / bungy jumping.

20 He incluido solo las palabras base, sin las derivaciones. 
delco $m$ (< marca registrada formada con las siglas de Dayton Engineering Laboratories Co., Obio, en inglés se emplea distributor) - rozdel'ovač;

eslinga $f(<$ sling, id.) - poprub, remeň, gurtňa;

ferry $m(<$ ferry, id. $)-$ trajekt;

flash $m$ (> flash, id.) - blesk;

flipar intr. coloq., argot (< inglés norteamericano to flip out) baluzit', mat' baluze; byt' natripovaný; byt' mimo, byt' blázon;

formica $f(<$ marca registrada por los estadounidenses Herb Faber y Don O'Connor, formado a partir de for mica, ya que fue inventado para reemplazar la mica, un tipo de aislante natural, Rodríguez González, 1997: 225) - umakart;

iceberg $m$ (< iceberg, id.) - l'adovec;

jersey $m$ (< jersey, id.) - sveter;

kart $m$ (< kart, id., abreviatura de go-kart) - motokára;

kleenex $m$ (< marca registrada Kleenex) - papierové vreckovky;

mildiu $m$ (< mildew, id.) - peronospóra, pleseň viničová;

parchís $m$ (< nombre de marca parcheesi $<$ hindi pachisi, antiguo juego indio similar al backgammon, Rodríguez González, 1997: 376) - Človeče, nehnevaj sa ${ }^{22}$;

quad $m$ (< quad, id.), sin.: cuadrimoto - štvorkolka f;

(cámara) réflex $f(<$ reflex, id.< latín reflexus 'reflejo') - zkradlovka, zrkadlový fotoaparát;

royalties $m p l$. (< royalties, id.), sin.: regalías - tantiémy, honorár;

stick $m$ (< bockey stick, la acepción originaria del apelativo stick es 'palo'), sin.: palo $m$ de bockey - bokejka (palabra derivada de la base bokej < inglés bockey);

top-less adj. / adv. (<topless, id.) - bore bez $z^{23}$;

21 Existe también el anglicismo suéter, sinónimo de jersey, que se emplea en Hispanoamérica.

22 Juego de mesa muy popular en Centroeuropa, prácticamente idéntico al parchís, surgió en Alemania y de ahí se calcó el nombre: Mensch ärgere Dich nicht 'Hombre, no te enfades'.

A veces se emplea el anglicismo topless también en eslovaco, pero es de uso poco frecuente. 
tupper $m$, tupperware ${ }^{24} m$ (del nombre de la marca Tupperware) - obedár;

walkie-talkie $m$ (<walkie talkie, id.) - vysielačka;

yearling $m$ (< yearling, id., derivado de year 'año') - jednoročiak, jednoročný žrebec;

zapping $m$ (<zapping, id., de origen onomatopéyico)-prepinanie programov, branie sa sovládačom.

\section{Anglicismos que se usan solo en eslovaco}

bojler $m$ (< boiler, id.) - calentador (de agua), caldera

dabing $m$ (< dubbing, id.) - doblaje

deadline $m$ informal (< deadline, id.) - fecha limite, fecha tope, vencimiento

dredy m pl. coloq. (< abreviado de dreadlocks) - rastas

dressing $m$ (<dressing, id.) - aliño, aderezo, salsa

ď̌em $m$ (<jam, id.) - mermelada, confitura

$d \check{z} o b m$ coloq. (< job, id.) - trabajo, empleo

džús $m$ (< juice, id.) - zumo

exitpol $m$ (< exit poll, id.) - sondeo a boca de urna, encuesta a pie de urna

grapefruit $m$, grep $m$ coloq. (< grapefruit, id.)

bosteska $f(<$ bostess, id.) - azafata

bumbug $m$ (< bumbug 'engaño'; 'tonterías') - bombo, escándalo

keks $m$ (< cakes pl. 'pasteles') - galleta

maskara $f$ (< inglés mascara < español máscara $\left.{ }^{25}\right)$ - rímel (< término derivado de la marca registrada francesa Rimmel, según su inventor Eugène Rimmel)

24 En México y Centroamérica también lonchera, derivada de lonche < inglés lunch 'almuerzo'. En España también se usa como sinónimo fiambrera.

25 http://etymonline.com/index.php?term=mascara\&allowed_in_frame=0 [12.06.2015]. 
second-band $m$, sekáč coloq. $m$ - tienda de ropa usada, tienda de ropa de segunda mano

skipass $m$ (<ski-pass, id.) - forfait

skóre $n$ (< score) - puntuación, marqueo, tanteo

smajlik informal $m$ (< smiley, id., derivado de smile 'sonrisa') emoticón, emoticono

šejk $m$ (< shake, id., del verbo to shake 'agitar', 'sacudir') - batido

zips $m(<z i$ (-fastener $)$, id. $)$ - cremallera ${ }^{26}$

\section{Conclusión}

A pesar de las tendencias unificadoras y de la fecha reciente de la presencia de la mayoría de los anglicismos, podemos observar claramente ciertas diferencias en su uso en las lenguas española y eslovaca. Las diferencias gráficas y fónicas son naturales dadas las predisposiciones de estas dos lenguas, que conducen a los anglicismos hacia la adaptación e inclusión orgánica dentro del sistema de cada lengua. Entre otras diferencias, se nota una mayor tendencia a añadir un sufijo sustantivador para convertir los sustantivos ingleses en elementos orgánicos del léxico eslovaco. En cuanto a las siglas vemos que el eslovaco mantiene en muchos casos la forma inglesa, mientras que el español tiende a castellanizarlas. Curioso es el caso de los pseudoanglicismos que se acuñaron en francés y pasaron al español. Ante la oleada de anglicismos las dos comunidades lingüísticas reaccionan a veces idénticamente, a veces de modo distinto, bien aceptando el préstamo íntegro y permitiéndole pasar de la periferia hacia el núcleo del léxico, bien creando un calco o neologismo semántico o sintáctico a fin de disponer de una palabra que denote el concepto semántico en cuestión. Finalmente, no podemos olvidar la posición del concepto en la realidad extralingüística, desde el exotismo hasta ser un elemento inherente de la realidad cotidiana de los hablanbtes hispanófonos y eslovacos.

\section{Bibliografía}

Corpes XXI, Real Academia Española. [en línea]. Disponible en: http://www. rae.es/recursos/banco-de-datos/corpes-xxi [12.06.2015].

Diccionario de la lengua española, Real Academia Española. [en línea]. Disponible en: http://www.rae.es/recursos/diccionarios/drae [12.06.2015].

26 En México y Centroamérica se emplea zíper < inglés norteamericano zipper 
Etymonline. [en línea]. Disponible en: http://www.etymonline.com [12.06.2015].

Gómez Capuz, J. (2004): La inmigración léxica. Madrid: Arco Libros.

Gómez Capuz, J. (2005): Préstamos del español: lengua y sociedad. Madrid: Arco Libros.

Rodríguez González, F. (dir.) (1997): Nuevo diccionario de anglicismos. Madrid: Gredos.

Slovenské slovniky. [en línea]. Disponible en: http://slovniky.juls.savba.sk/ [01.06 - 12.06.2015].

Slovenský národný korpus. [en línea]. Disponible en: http://korpus.juls.savba. $\mathrm{sk} /[01.06-12.06 .2015]$.

\section{Abreviaturas usadas}

adj. - adjetivo

adv. - adverbio

coloq. - coloquial

com. - sustantivo común

$\mathrm{f}$ - sustantivo femenino

intr. - verbo intransitivo

$\mathrm{m}$ - sustantivo masculino

$\mathrm{n}$ - sustantivo neutro

pl. - plural

sin. - sinónimo

tr. - verbo transitivo 
Bohdan Ulašin

University Comenius of Bratislava

\section{Lexical Anglicisms in Spanish and Slovak: a Contrastive Study.}

Key words: anglicism, false friend, Spanish, Slovak, calque.

This article compares two languages, Castillian Spanish and Slovak and contrasts the status and use of English loanwords in each language. It is a small part of a larger project comparing the lexical and semantic levels of both languages. The article classifies and gives examples of differences in the treatment of anglicisms between the two, starting with phonetic differences (introducing the most notable ones), orthographic, semantic and structural differences, then looking at synonyms and calques and ending with a discussion of the presence or absence of anglicisms in the cases of denotative mismatches. We also emphasize the importance of taking into account the cultural equivalent of the English loanwords in the extralinguistic reality of Spain and Slovakia. The phenomenon of so called pseudo-anglicisms in Spanish is mentioned, as well as the extremely numerous presence of false friends in Spanish (in comparison with Slovak). The article summarises the most typical differences between European Spanish and American Spanish varieties with regard to English loanwords. The article also discusses the case of acronyms, contrasting the use of English international acronyms in Slovak with the tendency to translate them in Spanish. 
Bohdan Ulašin

Univerza Komenskega v Bratislavi

\section{Leksikalni anglicizmi v španščini in slovaščini: primerjalna študija}

Ključne besede: anglicizem, lažni prijatelj, španščina, slovaščina, kalk

Prispevek sooča dva jezika, španščino in slovaščino, ter primerja položaj izposojenk iz angleščine $\mathrm{v}$ obeh jezikih. Umešča se $\mathrm{v}$ okvir širše primerjalne raziskave o pomenskih ter leksikalnih razmerjih med obema jezikoma. Prispevek sprva uvaja razvrstitev in najznačilnejše primere glasoslovnih razmerij, v osrednjem delu razdela pravopisna, pomenska in strukturna razmerja, v zaključku pa se posveti tudi razčlembi prisotnosti oziroma odsotnosti anglicizmov v primeru nesovpadanja denotativnih inačic med obema jezikoma. Razprava izpostavi pomen upoštevanja kulturnih inačic izposojenk iz angleščine v zunajjezikovni stvarnosti Španije in Slovaške. Poleg tega opredeli pojav tako imenovanih psevdoanglicizmov $\mathrm{v}$ španščini, ki ne sovpadajo $\mathrm{z}$ izvornimi izrazi v angleščini, ter pogost pojav navidezno sorodnih izvornih dvojic besed $\mathrm{v}$ španščini in angleščini, ki je v slovaščini, denimo, manj prisoten. Razprava pojasni tudi osrednje razlikovalne značilnosti med evropsko in latinskoameriško španščino glede na prisotnost anglicizmov v vsaki od omenjenih različic ter jih dodatno osvetli s primeri rabe anglicizmov v mednarodnih kraticah, ki v slovaščini pogosto nastopa kot sredstvo označevanja, v španščini pa kot težnja pri prevajanju. 